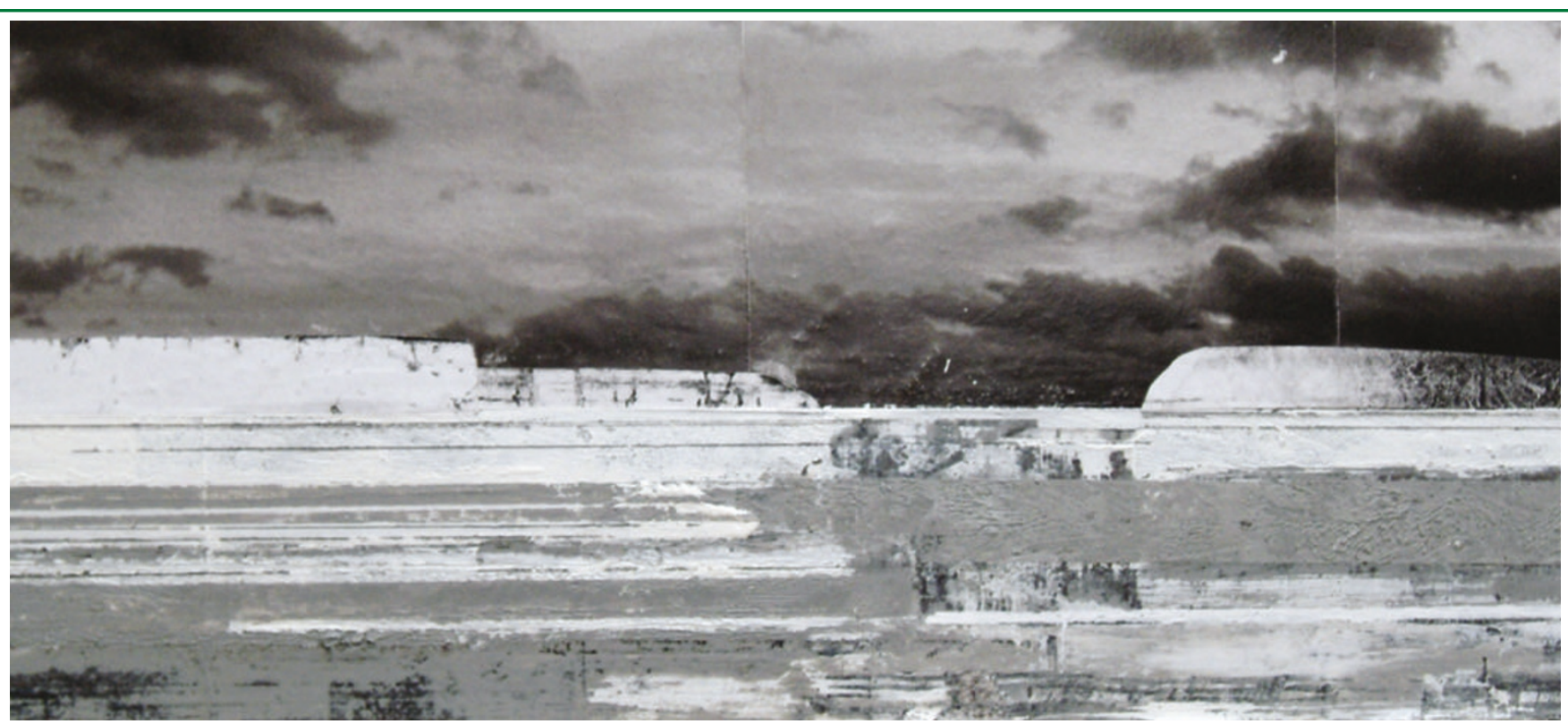

Art

\title{
Go with the floe
}

During his three-month sojourn with the British Antarctic Survey, artist John Kelly experienced the polar region as sublime but often darkly ominous. This painted-over photomontage - part of a six-part series called Silent Sea - portrays the Antarctic's threatening beauty. It is part of an exhibition of his work, "Due South: Art and the Antarctic", which runs from 24 February to 1 August at the Natural History Museum in London.

Alison Abbott

\section{A recipe for the mind}

\section{The Birth of the Mind: How a Tiny Number of Genes Creates the Complexities of Human Thought by Gary Marcus \\ Basic Books: 2004. 240 pp. \$26, £19.99}

\section{Anthony P. Monaco}

If the mind can be explained from the workings of the brain, and the brain develops by direction from our genes, then presumably the mind can be explained from our genetic make-up. But how can only 30,000 genes make a brain with billions of neurons and encode the particular aspects of cognition that make us human?

The Birth of the Mind tries to unravel this complex problem by first explaining what we know about each component of the argument: the mind, the brain, our genes and the environment. The breadth of examples used to achieve this is impressive, encompassing 40 different organisms (from bacteria to chimpanzees), 30 different genes and 20 different brain regions.

The author, Gary Marcus, spends much of his efforts building up the reader's knowledge base. It is difficult to make an argument that involves such diverse disciplines as evolution, genetics, gene expression, cell biology, neurobiology and psychology without teaching the reader the bare essentials. Marcus does particularly well to make the relevant issues in these areas understandable to the lay reader, and does an even better job of dispelling the myths that impede the way we think about genes and their role in making brains, and hence minds.

Marcus is a cognitive psychologist who understands genes. He has researched his topic well and describes the complex world of genes in an entertaining and gripping way. He dispels the myth that there are too few genes by explaining that single genes can encode several proteins with different functions, and more importantly that genes can be turned on and off in groups in multiple combinations to perform highly orchestrated and complex functions. He discards the analogy of genes as blueprints for building a brain (or any other organ in the body), and prefers to think of genes as the 'recipe' required for the correct development of the brain. He explains heritability and the difference between single-gene effects - and their resulting monogenic and relatively rare diseases - and complex genetic interactions, which cause more common diseases.

He also unravels the paradox of flexibility. How does the brain of a newborn, with its complex structures and connections, have the plasticity to enable it to respond to environmental influences as it develops further? Marcus disentangles the nature-versus-nurture argument using many examples from neuroscience research that show that the brain is built by genes in a self-organized way before being reorganized and shaped by experience and the environment. It is not a battle where one side wins, but a vital interaction.

Having clarified these two paradoxes using our current knowledge of genetics and neuroscience, can we explain how genes make minds? The story is only beginning. This book shows that genes build brains and that brains are designed to be flexible and to learn, but the jump from genes to the mind is an indirect one. The question cannot yet be answered, and it is not entirely clear where the answer will come from.

Will geneticists pinpoint genes and gene pathways that will inform us about human cognition? This is already happening but will provide only part of the answer and confirm that genes are directly influencing mental abilities. Will cognitive scientists detail the relationship between neural structures and mental structures? This area of research is expanding, thanks to modern brain-imaging techniques that enable researchers to 'see' the brain in action. The path ahead to integrate these disciplines to gain a fuller understanding is optimistically vague, and anyone interested in the topic would be encouraged to read this book.

Lay readers may be daunted by the sheer complexity of the science - even with the best intentions of explanations in lay terms, a glossary and an appendix to explain the genes. But the more scientifically minded, especially those with a background in either genetics or neuroscience, would gain much from the book. It would at least dispel some myths and paradoxes, leaving the possibilities open for an eventual understanding of how 30,000 genes can provide the recipe for the mind.

Anthony P. Monaco is director of the Wellcome Trust Centre for Human Genetics, University of Oxford, Headington, Oxford OX3 7BN, UK. 